\title{
Development and Status of Personnel Deployment Simulation and its Inclusion into the Digital Factory
}

\begin{abstract}
Gert Zülch*
ifab-Institute of Human and Industrial Engineering, Karlsruhe Institute of Technology, Kaiserstrasse 12, 76131 Karlsruhe, Germany; *gert.zuelch@gefora-beratung.de
\end{abstract}

SNE 30(4), 2020, 197-202, DOI: 10.11128/sne.30.tn.10541 Received: July 13, 2020 (Selected ASIM SPL 2019 Postconf. Publ.); Revised: Oct. 11, 2020; Accepted: Oct. 20, 2020

SNE - Simulation Notes Europe, ARGESIM Publisher Vienna ISSN Print 2305-9974, Online 2306-0271, www.sne-journal.org

Abstract. The development of personnel deployment simulation started just before 1980 . To the first, more production-logistics-oriented simulation procedures, macroergonomic features have been added, i.e., mainly solving capacity- and utilization-related problems. The current status is characterized by the integration into tools of the Digital Factory, which increasingly includes micro-ergonomic considerations. Above all, anthropometric and physiological questions of human operations predominate. In addition to these aspects aiming at the human work task itself, the focus is currently also placed on the work environment that the working person is exposed to. This is currently still the focus of research and development related to ergonomics and occupational health and safety. With regard to further steps, there is a particular need to better link discrete event simulation procedures with Digital Factory tools. Thereby, also strong demands on ergonomic research are made. This is shown, e.g., in the still unsolved problem that types of stress acting together on the working human cannot be assessed in common.

\section{Introduction to Considering the Staff in the Digital Factory}

The inclusion of personnel deployment simulation in tools of the Digital Factory is an essential part of plant planning today, or at least it should be. It makes it possible to plan the future workforce in the factory in advance, not only in terms of numbers, but also with regard to the necessary qualifications of the employees.
In this way, the productivity of the individual work systems can be forecast, analyzed for weak points and secured before the factory goes operational.

However, this rather production-logistical view of future personnel deployment is no longer sufficient today. Questions are also asked about the expected stress and strain on the staff as a result of the assigned work tasks. Related tools already exist, the focus being on the stresses and less on the effects on the working person, the strains. Therefore, the focus of development is increasingly placed on aspects of occupational health and safety.

The endeavors to analyze the effects of the spatial environment on the working person as early as in the planning stage of a factory are relatively new. These effects can not only lead to a reduction in productivity, but above all to impair the health of employees. But, in this regard, primarily isolated software tools are available and only very few of them are already integrated into the Digital Factory procedures.

The mentioned aspects of the personnel-related expansion of the Digital Factory are discussed in more detail below. This is done on the basis of guidelines from the Association of German Engineers, some of which are still being worked on. Current developments and trends are discussed and illustrated by some selected application examples.

\section{Basic Requirements for Personnel Deployment Simulation}

In principle, personnel deployment simulation encompasses all areas of work system planning: It extends from the flow of materials and information, with the involvement of people, to the production-logistic analysis of work systems. 
Furthermore, the question of the division of labour under qualification aspects and the human cooperation in parts manufacturing and assembly systems as well as the design of working methods at individual workplaces are regarded. From its early developments on, the presentation of result scenarios in tools of the Digital Factory plays an essential role.

A fundamental requirement for personnel deployment simulation is the modelling of personnel qualifications. What is essential here, is the separation into machine and personnel simulation objects that are related to one another in the simulation process via functions (in particular work activities). This largely corresponds to the requirements of time management according to the REFA methodology ([1]; see also [2]). With the help of these simulation objects, the responsibility of workforce for machines or workplaces, the requirements and abilities needed, and the feasibility of functions and, thus, the qualification of a person or type of personnel can be modelled (Figure 1). The personnel deployment simulation differs significantly from the purely production-logistics one, which generally treats people and machines as an integrated resource.

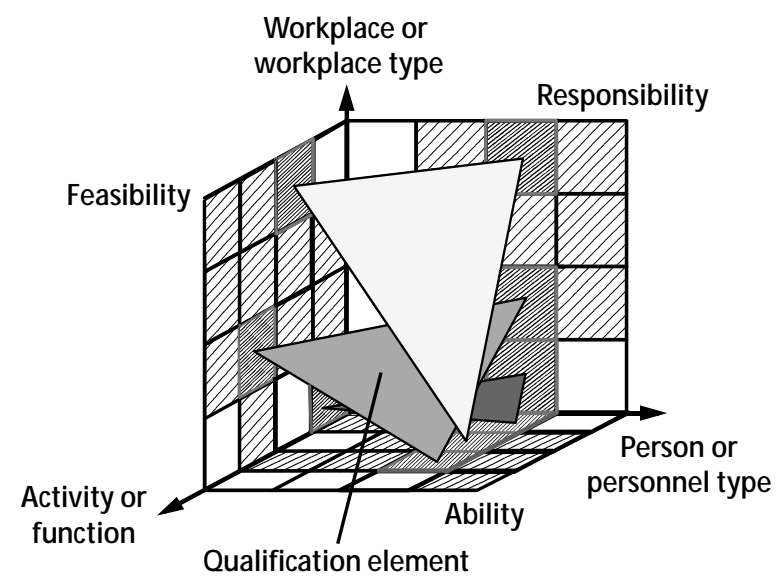

Figure 1: Modelling the qualification as part of the personnel deployment simulation (according to [3], p. 53).

At the international level, personnel deployment simulation receives relatively little attention. Static methods of calculating personnel requirements dominate here, especially through using spreadsheets. Dynamic analyses with the help of simulation with its necessary separation of human operators and technical equipment are largely ignored.
A typical example for the consideration of personnel in the production area is provided by Mounsey et al. [4]. The authors take into account the costs of different shift systems and staff assignment, but do not consider the qualifications of the individual employees.

When it comes to personnel deployment problems, the focus is mainly on service areas, e.g., on hospital operations [5] or call centres [6], whereby optimization and simulation methods are occasionally combined (e.g., [7]). In contrast to the modelling of production operations, simplifications are often possible in the service sector, so that a part of the equipment and its operator can be viewed as one resource. Furthermore, as a rule, only uniform qualifications of all employees are very often assumed.

\section{Production-Logistics-oriented Personnel Deployment Simulation and the VDI Guideline 3633 Part 6}

The application field of personnel deployment simulation were initially parts production and assembly systems (see the overview at [8]). The first dissertations on this subject appeared in Germany in 1980 almost simultaneously at the RWTH Aachen University and the University of Stuttgart. Since these first publications, personnel deployment simulation in Germany has a history of forty years. This effort was reflected by the German Association of Engineers in their Guideline VDI 3633 Part 6 from 2001 [9], which is currently being revised.

In this context, a new possibility of modelling will also be discussed: While it is well-known that the precedence graph can be used to describe work processes, this graph itself can be mapped onto a capacity graph of the stations in the work system and, in the case of multi-station operation, the latter in turn can be mapped onto a staff assignment graph of the employees providing the basis for simulation (Figure 2).

An actual example from production logistics is the investigation of what influence demographic development may have on the productivity of a work system. The basis for such an investigation is the well-founded assumption that the performance decreases with the age of an employee (see already [10], pp. 518). A study for an assembly line showed a decrease in the output of the work system of around $13 \%$ over a period of 14 years [11]. 


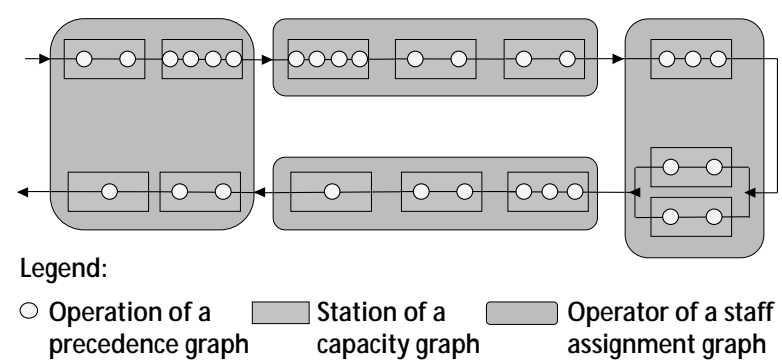

Figure 2: Precedence, capacity and staff assignment graph of a U-shaped assembly system.

Müller et al. [12] pursue an approach using their WorkDesigner software which combines personnel planning in the production area with macro-ergonomic aspects. The aim is to take into account not only the use of resources, but also the individual ability to work and the age of the simulated employees.

Subsequently, the application field of personnel deployment simulation was extended to service areas. In line with the social discussion, in addition to questions of production performance, the focus was also on the organization of working time with regard to the work-life balance of the employees. Thus, productivity-related evaluation was connected to social-psychological effects.

An example of this was provided by a study in a selfservice department store ([13], p. 166). To investigate the effect of different working time systems on the work-life balance, the potential working time conflicts of the employees were first recorded and then anonymized using a cluster analysis. Seven full-time and seven part-time staffing models were combined with the working time systems. These were finally combined with eight scenarios with $80 \%$ to $150 \%$ customer traffic and ten employee scenarios with different working time preferences.

Taking into account ten test replications, in total 3,920 scenarios were created, which were then statistically evaluated with regard to various target criteria. For this purpose, the concept of the degree of goal achievement was used, which normalizes the original values in a range of $0 \%$ for the theoretically worst and $100 \%$ for the optimal result.

As expected, the degree of goal achievement shows contrary trends with regard to the throughput time of the customers and the utilization of the employees (Figure 3). The potential for temporal conflicts, on the other hand, hardly varies: However, this is due to the fact that with one conflict per hour a very strict measure for worst values was defined, so that optimal values of $100 \%$ could be reached relatively easily. Working time systems with a higher proportion of flexitime proved to be favourable (see an example from the logistics area at [13], p. 201).

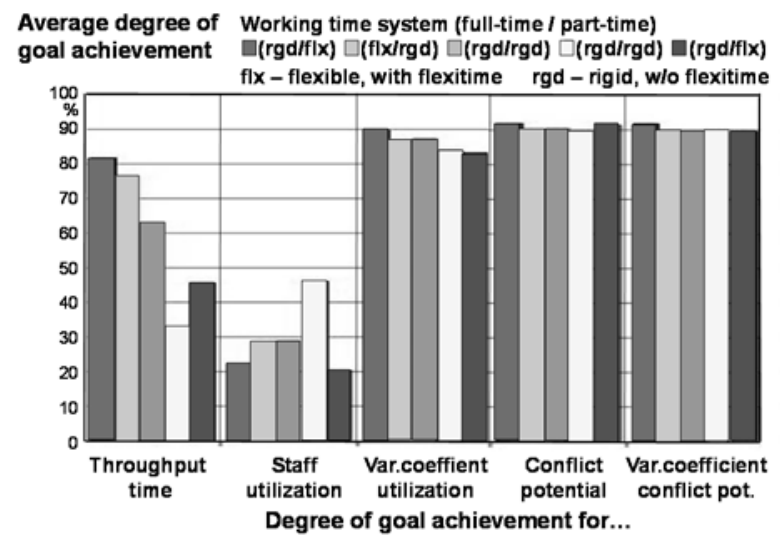

Figure 3: Average degree of goal achievement for selected working time systems in a self-service department store (according to [13], p. 192).

\section{Stress Originating from the Work Task and the VDI Guideline 4499 Part 4}

The main focus of the development is the connection of human models with tools of the Digital Factory, which already dates back to the 1960s. Regarding human models and the associated analysis and visualization of ergonomic effects originating from the work task, a number of methods and software tools from the American and English area (see the overview at [14], p. 44) are available.

In this regard, the VDI guideline 4499 part 4 from 2015 [15] deals with the micro-ergonomic effects of the work task, preferably at an individual workplace. Present methods primarily aim at the analysis of anthropometric and work physiological stress. This has already been discussed in more detail earlier [16].

Such analyses already found their way into tools of the Digital Factory at an early stage, as the example of the redesign of one of the Adam Opel AG plants in Germany from 2001 demonstrates [17]. Figure 4 shows the NIOSH assessment of a lifting task [18] using the eM-Engineer software [19] as another early example. The Gantt chart illustrates the possibility of connecting to a discrete event simulation; it shows the actual work situation for which the ergonomic assessment is carried out. 


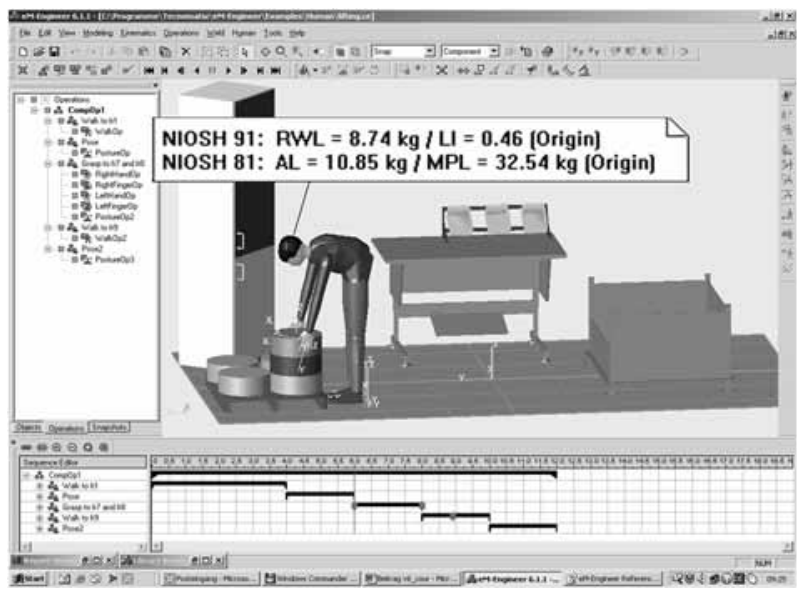

Figure 4: Ergonomic evaluation of a lifting task using the software eM-Engineer [19].

\section{Influences from the Working Environment and the Draft Guideline VDI 4499 Part 5}

The principles of ergonomics, especially its stress-andstrain concept [20], require consideration of external exposures or stresses as well as internal (physiological or mental) strains of the individual employee who is exposed to these stresses. The ambition is to determine the various physical (e.g., cardiovascular problems) and sometimes chemical effects (e.g., through skin-receptive hazardous substances) in Digital Factory tools on the basis of a uniform data model of the work space. The need to forecast environmental influences on working people was already pointed out at an early stage [21]. A guideline committee is currently working in a project devoted to prepare the corresponding guideline VDI 4499 Part 5 ([22]; see also [23]).

Internationally, there is almost no evidence for the virtual prediction of stresses and strains from the working environment. But, also in the German-speaking area, which the named draft guideline project is focusing on, the majority of the relevant procedures remain with isolated solutions for evaluating individual environmental factors without including them into tools of the Digital Factory. Above all, it is about the visualization and assessment of exposures or stresses, while strains of working people are only considered in very few software procedures.

In addition to the scientifically unsolved problem of integrally merging combined environmental influences on working people in a uniform key figure, there are still gaps in the time-related and personal-oriented assessment, even for individual factors. In this regard, there are primarily point-in-time evaluation methods for stresses and their assessment in terms of occupational health and safety.

An existing example of personal exposure is that caused by gamma rays in a work area ([24]; Figure 5). The procedure is based on the ALARA principle (As Low As Reasonably Achievable), which requires such a low radiation exposure of the working person, "as it seems feasible when considering practical reason and weighing up advantages and disadvantages" (translated from [25]). It enables not only a point-in-time evaluation of the radiation exposure, but also a period-related one, which is represented by means of a virtual dosimeter through incorporating discrete event simulation. In addition, the form of work organization can be assessed when deploying several people in the same work area.

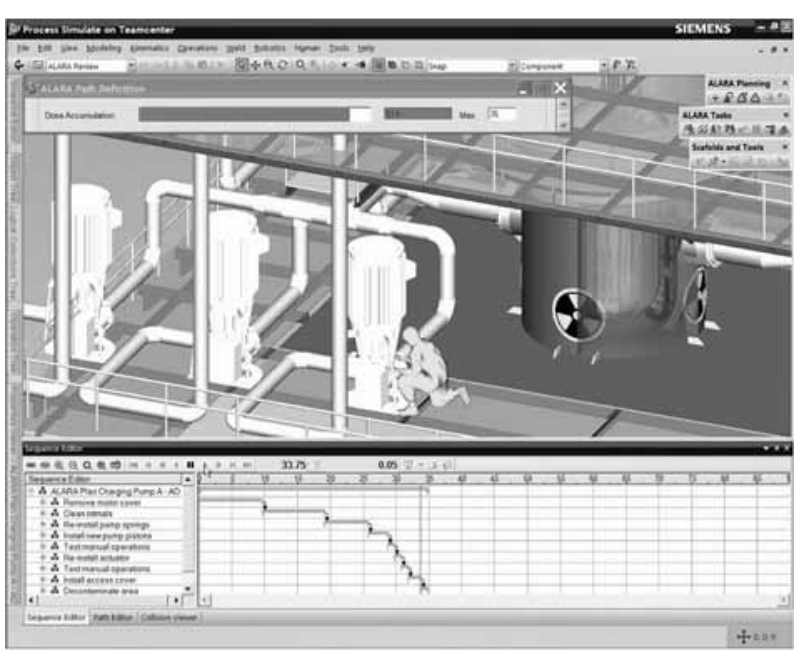

Figure 5: Visualization of the work situation in a radiation-exposed work area and its Ganttchart representation [24].

\section{Further Development of Integrating Personnel Deployment Planning into the Digital Factory}

The coupling of discrete event simulation and its visualization in the Digital Factory is by no means trivial, since the modelling approaches of both types of software are very different: While the former may follow the depiction of workflows for months and focusses primarily on the presentation in the form of business graphics, the latter follows a realistic graphic animation at most in the minute range. 
As an interim result of the personnel deployment simulation and its inclusion into the Digital Factory, it can be stated that this desirable coupling has already reached a certain level, which has led to the publication of several VDI guidelines. However, some essential aspects remain unaffected: The inclusion of occupational psychological and sociological aspects is particularly noteworthy, as there is a lack of evaluation and assessment methods that can be used in discrete event simulation. There is also a lack of options for integrally evaluating multi-factor stress. The use of a lexicographical preference ordering can only provide a substitute solution ([26], p. 42).

One obstacle is that many ergonomic evaluation procedures are only available as isolated software solutions, which are not yet integrated into Digital Factory tools. This is all the more true for the assessment of determined values: limit values for a number of stresses are available for the assessment. However, since these are only available as text, they can only be inserted manually into the respective procedures. An additional key point will, therefore, be the problem that the normative values that are necessary for assessing the work situation are not yet made available in an adequate information technology manner ([21], p. 221).

Related to time-based analysis, the question also needs to be clarified as to whether a REFA-based modelling is better suited for an integration than one derived from resources. Since practice is interested in suitably considering both views at least in parts, new research questions arise. In addition, it must also be clarified which modelling method is more suitable for an ergonomic evaluation and assessment.

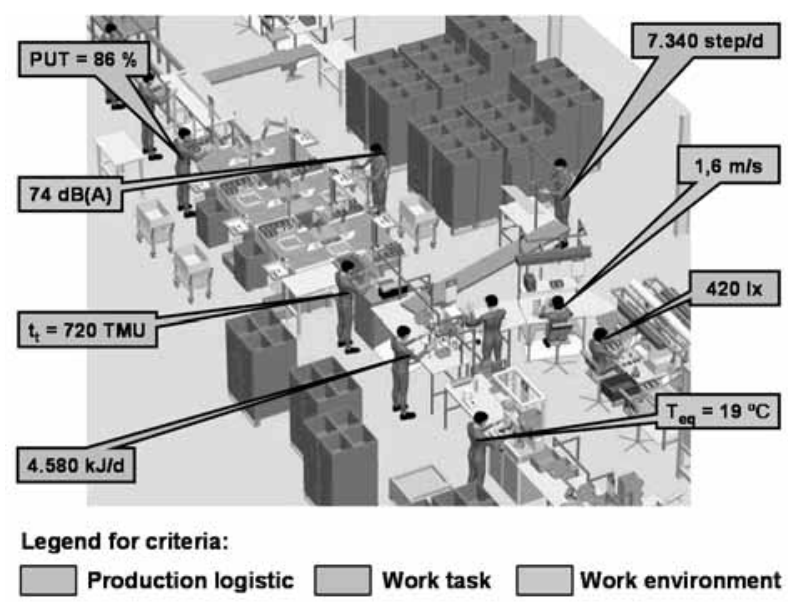

Figure 6: Vision of stress forecasts in the Digital Factory (Layout software: Ergomas; see [27], p. 215).
The existing obstacles for considering ergonomic aspects in the Digital Factory give rise to the further development of the related tools. The vision of the forecast is to provide not only production-logistics criteria, but also ergonomic ones for the evaluation and assessment of stresses caused by the work task and the work environment (Figure 6). However, a comprehensive forecast of strain on working people will probably still be a long way off.

\section{References}

[1] REFA - Bundesverband, editor. REFA-Lexikon. München: Hanser; 2011.

[2] Fricke W. Arbeits- und Zeitwirtschaft verstehen. Norderstedt: Books on Demand; 2016

[3] Zülch G, Waldherr M, Zülch M. Challenges for the provision of process data for the Virtual Factory. In: Dangelmaier W, Blecken A, Delius R, Klöpfer S, editors. Advanced Manufacturing and Sustainable Logistics. Berlin, Heidelberg: Springer; 2010, 46-56.

[4] Mounsey S, Hon B, Sutcliffe C. Performance modelling and simulation of metal powder bed fusion production system. CIRP Annals - Manufacturing Technology. 2016; 65: 421-424.

[5] Ghanes K, Wargon M, Jouini O, Jemai Z, Diakogiannis A, Hellmann R, Thomas V, Koole G. Simulationbased optimization of staffing levels in an emergency department. Simulation. 2015; 19(10): 942-953.

[6] Woo Kim J, Ho Ha S. Consecutive staffing solution using simulation in the contact center. Industrial Management \& Data Systems. 2010; 110(5): 718-730.

[7] Corominas Subias A, Lusa Garcia A. LETRIS: Staffing service systems by means of simulation. Journal of Industrial Engineering and Management. 2012; 5(2): 285-296.

[8] Zülch G. Vier Jahrzehnte personalorientierte Simulation - Rückblick und Ausblick. In: Gesellschaft für Arbeitswissenschaft, editor. VerANTWORTung für die Arbeit der Zukunft. Dortmund: GfA Press; 2015: 6 pages.

[9] VDI 3633-6:2001-10 Simulation of systems in materials handling, logistics and production - Representation of human resources in simulation models. Berlin: Beuth.

[10] Baines T, Mason S, Siebers P. Ladbrook J. Humans: The missing link in manufacturing simulation? Simulation Modelling Practice and Theory. 2004; 12(7-8): $515-526$.

[11] Zülch G, Becker M, Linsenmaier W. Modelling and simulation of human performance changes in assembly systems due to aging. In: International Ergonomics Association, editor. $17^{\text {th }}$ World Congress on Ergonomics IEA; 2009 August 9-14; Bejing. CD-ROM. 
[12] Müller W, Gust, P, Feller N. WorkDesigner: Consulting application software for the strain-based staffing and design of work processes. Procedia Manufacturing. 2012; 3: 379-386.

[13] Leupold M. Simulationsbasierte Gestaltung von Arbeitszeitsystemen in Dienstleistungsbetrieben unter Berücksichtigung der Work-Life-Balance. Aachen: Shaker; 2018.

[14] Bullinger-Hoffmann AC, Mühlstedt J. Homo Sapiens Digitalis - Virtuelle Ergonomie und digitale Menschmodelle. Heidelberg: Springer; 2016.

[15] VDI 4499-4:2015-03. Digital factory - Ergonomic representation of humans in the digital factory. Berlin: Beuth.

[16] Zülch G. Ergonomische Abbildung des Menschen in der Digitalen Fabrik - Die neue VDI-Richtlinie 4499-4. In: Dangelmaier W, Laroque C, Klaas, A. Simulation in Produktion und Logistik 2013. Paderborn: HNI-Verlagsschriftenreihe; 2013: 53-60,

[17] Adam Opel AG, editor. Neues Werk Rüsselsheim. Rüsselsheim: Opel Communications; 2001. CD-ROM.

[18] Middlesworth M. A step-by-step guide to using the NIOSH lifting equation for single tasks. https://ergoplus.com/niosh-lifting-equation-single-task, accessed 11.07.2020.

[19] Tecnomatix, editor. eM-Engineer. http://www. tecnomatix.com, accessed 04.02.2004.
[20] Rohmert W. Ergonomics: Concept of work, stress and strain. In: Applied Psychology. 1986; 35(2): 159-181.

[21] Keller V, Zülch G. Repräsentation von Arbeitsschutzdaten und ihre Visualisierung in rechnerunterstützten Managementsystemen. In: Zülch G, Brinkmeier, B, editors. Arbeitsschutz-Managementsysteme. Aachen: Shaker; 2000: 219-229.

[22] VDI 4499-5 - Projekt. Digitale Fabrik - Prognose von Umgebungseinflüssen auf den arbeitenden Menschen. https://www.vdi.de/richtlinien/details/vdi-4499-blatt-5digitale-fabrik-prognose-von-umgebungseinfluessen-aufden-arbeitenden-menschen, accessed 13.07.2020.

[23] Illmann B, Fritzsche L, Ullmann S, Leidholdt W. Ganzheitliche Gefährdungsbeurteilung mit digitalen Menschmodellen - Die Integration von Umgebungsbedingungen in die Digitale Fabrik. In: Gesellschaft für Arbeitswissenschaft, editor. VerANTWORTung für die Arbeit der Zukunft. Dortmund: GfA Press 2015; 6 pages.

[24] Siemens PLM Software, editor. ALARA planning using Jack and Microsoft Kinect. https://www.youtube.com/ watch?v=pCCBDODA0nM. Status 03.08.2012, accessed 13.07.2020.

[25] Wikipedia, editor. ALARA. https://de.wikipedia.org/wiki/ ALARA, accessed 21.06.2018.

[26] Zülch G, Zülch M. Production logistics and ergonomic evaluation of U-shaped assembly systems. International Journal of Production Economics. 2017; 190: 37-44.

[27] Menges R, Eigenmann U. Design for production facilities. In: Bullinger HJ, Warschat J, editors. Concurrent Simultaneous Engineering. London: Springer; 1996: 215-227. 